\title{
LA CONFORMACIÓN DE LA ANTROPOLOGÍA COMO DISCIPLINA CIENTÍFICA, EL MUSEO NACIONAL DE MÉXICO Y LOS CONGRESOS INTERNACIONALES DE AMERICANISTAS
}

\author{
POR \\ JESÚS BUSTAMANTE GARCÍA \\ Instituto de Historia, CSIC ${ }^{1}$
}

En este trabajo se analiza el proceso por el que el Museo Nacional de México, originalmente un museo que abarcaba todas las ramas del saber, alcanza su madurez institucional y su máxima significación social como un Museo de Antropología. Un caso de estudio que muestra la necesidad de replantear críticamente los presupuestos y teorías habitualmente más aceptados acerca del origen e institucionalización de la Antropología como disciplina.

Palabras claves: Museo Nacional, Antropología, Memoria Histórica, Población Nacional, Colonialismo.

En 1924, D. Luis Castillo Ledón, director por largos años del Museo Nacional de Arqueología, Historia y Etnografía de México (1914 a 1934, con breves interrupciones), se permitía decir lo siguiente:

«Puede asegurarse que no hay institución mexicana oficial que tenga mayor prestigio que ésta en el extranjero. El Museo sostiene relaciones epistolares con todas o casi todas las instituciones de su índole y afines que hay en el mundo, inclusive Asia y Africa. Sus publicaciones... le han dado renombre; por cierto, que es también la única institución nacional que ha merecido se le concediera, no ha mucho, el derecho de voto para la adjudicación del Nobel»².

1 Este trabajo se inscribe en el proyecto de investigación «Ingenieros Sociales. La construcción del método y el pensamiento antropológico en Europa e Iberoamérica, siglo XIX» (BSO2001-2341), financiado por la Dirección General de Investigación del Ministerio de Ciencia y Tecnología.

2 Luis Castillo Ledón, El Museo Nacional de Antropología, Historia y Etnografía, 18251925. Reseña histórica para la celebración de su primer centenario, México, Imprenta del Museo Nacional, 1924, p. 52 [también en la selección de textos elaborada por Luis Gerardo MorALES 
El orgullo es tan evidente como justificado, y esa institución, que corresponde a lo que hoy conocemos como Museo Nacional de Antropología de México, sigue siendo hasta ahora uno de los referentes de mayor prestigio y significación para la cultura e identidad mexicanas, tanto a nivel nacional como internacional. Ahora bien, la larga evolución seguida por ese museo — en cuanto a contenidos y en cuanto a objetivos - me parece del mayor interés para estudiar en general los procesos de institucionalización de las ciencias humanas y sociales, especialmente de la Antropología. De hecho, lo que este trabajo propone es que en América - muy en concreto en Latinoamérica - encontramos un caso de estudio que me parece todo un aldabonazo, toda una llamada de atención crítica frente a los presupuestos habitualmente sostenidos sobre el origen y conformación de la Antropología como disciplina.

Pero antes de entrar en esa cuestión, nuestro primer objetivo debe ser la reconstrucción, lo más clara y significativa posible, del complejo tránsito que siguió este museo mexicano desde un centro enciclopédico a una institución especializada precisamente en Antropología, pero manteniendo siempre lo «nacional» como referencia prioritaria y como objeto único de sus contenidos. Complicado proceso en el que, por cierto, dos Congresos Internacionales de Americanistas desempeñarían un papel decisivo como mecanismos de fijación y legitimación institucional, por el reconocimiento científico que aportaron y por las redes internacionales en las que la institución quedó inscrita.

\section{LAS RAÍCES Y PRIMEROS PASOS DE UN MUSEO NACIONAL}

El que hoy suele conocerse popularmente como Museo Antropológico, a secas, nació como Museo Nacional - también a secas y poniéndo el énfasis en el adjetivo «Nacional». Estamos hablando de una de las instituciones museísticas más antiguas de América. Es cierto que no sabemos muy bien con qué raíces coloniales entroncarlo, quizá el Gabinete de Historia Natural fundado en 1790 por José Longinos en relación con la Real Expedición Botánica a la Nueva España, o quizá la oficina de la Junta de Antigüedades creada en relación con la Real Expedición Anticuaria a la Nueva España que dirigió Guillermo Dupaix... Y por supuesto, hay otras posibilidades como las colecciones de la Academia de San Carlos, las del Colegio de Minería, las de la propia Universidad o todas ellas jun$\operatorname{tas}^{3}$. Sea como fuere, lo verdaderamente seguro es que Lucas Alamán consiguió

\footnotetext{
Moreno, Orígenes de la museología mexicana. Fuentes para el estudio histórico del Museo Nacional, 1780-1940, México, Universidad Iberoamericana, 1994, p. 101].

3 Para la historia de este museo, la obra de referencia — que incluye además una cuidada selección de los textos más importantes que disponemos al respecto- es la ya citada de Luis Gerardo MoRALES Moreno [2]; pero véase igualmente Luis Gerardo Morales Moreno, «History and Patriotism in the National Museum of Mexico», en Flora E.S. KAPA (ed), Museums and the Making of "Ourselves». The Role of Objects in National Identity, Londres, Leicester University Press, pp. 171-191.
} 
en 1825 que se dictara una orden para «que con las antigüedades que ... existen en esta capital se forme un Museo Nacional y que a este fin se destine uno de los salones de la Universidad», y a él se debe también el decreto de 1831 que dio existencia legal definitiva a ese museo ${ }^{4}$.

Aunque Lucas Alamán alude de forma directa a las «antigüedades», lo cierto es que el museo entonces fundado tenía un carácter general e incluía las artes, las técnicas y toda la Historia Natural ${ }^{5}$. Por los testimonios conservados, algunos de ellos gráficos, aquel museo ubicado en la vieja universidad formalmente se parecía mucho a una galería atestada o a un almacén ${ }^{6}$. A falta de mayores estudios, todo indica que su principal aportación fue la de introducir el principio de «bien patrimonial», referido a todo lo hallado en el suelo mexicano que fuere de «utilidad y lustre nacional». Por lo demás, parece que tuvo una existencia bastante vegetativa hasta que en 1865 el emperador Maximiliano — probablemente impulsado por las actividades y primeros resultados obtenidos por la Comisión Científica FrancoMexicana (Commission Scientifique du Mexique) ${ }^{7}$ - decidió dignificarlo, trasla-

4 Morales Moreno [2], pp. 36-37.

5 De hecho, en alguna parte he leído que se describe a este primitivo Museo Nacional como un «Museo de Antigüedades e Historia Natural», pero no puedo precisar la fecha exacta de esa referencia (que sin duda es decimonónica) ni el lugar donde la he visto.

6 Hay dos láminas muy ilustrativas al respecto. La primera es de Pedro Gualdi representando el claustro de la Real y Pontifica Universidad de México en cuyo centro se guardaba la estatua ecuestre de Carlos IV y en cuyas esquinas, protegidas por enrejados de madera, se exponían la Coatlicue y otras gandes «piedras» como la de Tizoc. La lámina forma parte del volumen Monumentos de Méjico, tomados del natural que Pedro Gualdi publicó, en la Imprenta Litográfica de Masse y Decaen, México, 1841. La segunda lámina, obra de Casimiro Castro, lleva por título "Antigüedades mexicanas que existen en el Museo nacional de México. 1857» y muestra el aspecto que tenía el gabinete arqueológico propiamente dicho. Esta segunda ilustración forma parte del volumen México y sus alrededores. Colección de vistas, trajes y monumentos, famosa serie de láminas litrográficas realizadas por C. Castro, J. Campillo, L. Auda y G. Rodríguez, publicadas por Decaen Editor, México, s.d. (pero c.1862). Manejo una reedición facsimilar mexicana, sin referencias de año ni editor.

7 A pesar de la importancia de esta expedición científica, parece que aún tiene pendiente un estudio monográfico que aborde toda su complejidad. Véase no obstante el venerable trabajo de Juan COMAS, Las primeras instrucciones para la investigación antropológica en México, 1862, México, UNAM, 1962; así como las referencias recogidas en Beatriz URIAS HoRCASITAS, Indígena y criminal. Interpretaciones del derecho y la antropología en México, 1871-1921, México, Universidad Iberoamericana, 2000, pp. 81-92. Véanse además los estudios de Leoncio LóPEZ-OCóN, «La Comisión Cientifica del Pacífico (1862-1866) y la Commission Scientifique du Mexique (18641867): paralelismos y divergencias de dos proyecciones latinoamericanas de la ciencia europea», en Alejandro Díez Torres, Tomás Mallo y Daniel Pacheco Fernánez (coords), De la Ciencia Ilustrada a la Ciencia Romántica, Aranjuez (Madrid), Ateneo de Madrid y Doce Calles, 1995, pp. 458-475; Alberto SOBERANIS, «La expansión geográfica de la ciencia: Orígenes históricos de la Commission Scientifique du Mexique», Revista del Seminario de Historia Mexicana (Guadalajara, Mex.), vol. 1, núm. 3 (1998), pp. 9-75; y Pascal RiviALE «La science en marche au pas cadencé: Les recherches archéologiques et anthropologiques durant l'intervention française au Mexique (1862-1867)», Journal de la Société des Américanistes 85 (1999), pp. 307-341. 
dándolo a una nueva sede ubicada al costado del propio Palacio de Gobierno, en la antigua Casa de la Moneda, donde se mantendría por los cien años siguientes. Debido a los acontecimientos históricos que se sucedieron, poco más pudo hacer y poco más se haría hasta la llegada de Porfirio Díaz (1876-1880 y 1884-1911), que a todos los efectos fue el auténtico impulsor de esta institución.

La primera fase en la consolidación del museo se produjo entre 1876 y 1889 , y corresponde a las direcciones de Gumersindo Mendoza y Jesús Sánchez, un farmacéutico y un botánico, a quienes se debe la primera organización general de las colecciones, la primera catalogación científica (publicada) y la fundación, en 1877, del primer órgano de expresión impreso, los Anales del Museo Nacional.

Al comenzar ese período - 1877- los fondos del Museo eran descritos como una mera colección de objetos pertenecientes a las Ciencias Naturales y a la Arqueología, en la que los jeroglíficos, piedras y demás objetos de barro permanecían «mudos», mientras que las plantas, animales y fósiles eran una «mera curiosidad» ${ }^{8}$. Este fue el cimiento al que se aplicaron las nuevas ideas y objetivos.

En 1880 el museo estaba dividido en tres Departamentos: Historia Natural, Arqueología e Historia. Por su parte, los fondos estaban adscritos a cuatro secciones: Historia Natural, Antigüedades, Objetos históricos y Objetos artísticos (esta última sección vinculada a la Escuela de Bellas Artes). El volumen de los fondos no era muy llamativo: una colección bastante limitada de antigüedades (aunque algunas importantes), la estatua ecuestre de Carlos IV, una serie de obras hechas por los artistas de la Academia de Bellas Artes y por los becados en Roma, dos colecciones de retratos de virreyes.... y sobre todo un fondo de Historia Natural: mil ejemplares de conchas y zoofitos, sesenta mil insectos, quinientos reptiles y pescados, doscientos mamíferos... Todos de México, porque se trata literalmente de un museo «nacional» que no aspiraba a ser universal, ni siquiera continental ${ }^{9}$.

La seriedad con la que se llevaron a cabo las primeras tareas de organización, catalogación y edición, favoreció la incorporación de nuevos materiales y de co-

8 Jesús SÁNCHEZ, «Reseña histórica del Museo Nacional de México», Anales del Museo Nacional de México, [1 época], vol. I (1877), pp. 1-2 [recogido en Morales Moreno [2], pp. 72-73]

9 La descripción general del Museo en esta fecha procede de Manuel Rivera CAMBAS, México pintoresco, artístico y monumental, México, Imprenta de la Reforma, 1880, tomo I, pp. 175-182 [puede consultarse más fácilmente en MORALEs MORENO [2], pp. 74-81]. Una descripción más detallada de las secciones histórica y arqueológica puede encontrarse en Gumersindo MENDOZA y Jesús SÁNCHEZ, «Catálogo de las colecciones históricas y arqueológicas del Museo Nacional de México», Anales del Museo Nacional de México, [1 $1^{\mathrm{a}}$ época], vol. II (1882), pp. 445-486. Por cierto la obra de Rivera Cambas, además de la descripción del Museo Nacional, incluye también una ilustración mostrando el conocidísimo Calendario Azteca en el lugar donde se expuso por largos años: «colocado en un costado de la Catedral, al Occidente, frente a la calle del 5 de Mayo». Es decir, cuando todavía no había sido incorporado al Museo. Luisa RILEY, «La piedra sin sosiego», Luna córnea 13 (sep.-dic. 1997), pp. 16-23, hace un curioso relato de las distintas ubicaciones que siguió este monumento y lo ilustra con fotografías, una de ellas de 1880-1885 (es decir, cuando aún estaba empotrado en una de las torres de la catedral mexicana). 
lecciones completas que mejoraron considerablemente los fondos del museo. Así el famoso Calendario Azteca, que desde su descubrimiento en 1790 se exponía al público en el lateral de una de las torres de la catedral, pasó a formar parte del museo en 1885 y tal acontecimiento sirvió de punto de partida para una remodelación total de la sección de antigüedades. El 16 de septiembre de 1887, fecha patria, se abrió al público una sala de arqueología totalmente remodelada, bajo el nombre de «Galería de Monolitos», en la que las esculturas aztecas más monumentales e imponentes venían a asumir la representación de la cultura prehispánica. Nacía una imagen de enorme vigor, mejor dicho, todo un imaginario.

El museo entraba así en su mayoría de edad, asumiendo la pedagogía patriótica como uno de sus objetivos prioritarios y definiéndose, al mismo tiempo, como una institución creadora y legitimadora de la historia oficial. Se trata de un punto de inflexión clave, en el que la institución basculó de forma decidida hacia su lado histórico y arqueológico. El museo no sólo contó a partir de entonces con el apoyo y la protección «oficial», sino que él mismo pasó a ser una de las instituciones claves en la definición de políticas como la arqueológica o la de protección del patrimonio nacional.

Entramos así en una nueva fase, datable entre 1889 (en que Francisco del Paso y Troncoso, médico de formación pero reconocido como «anticuario», asumió la dirección) y 1911 (en que comienzaron los años confusos de la Revolución). En ese período el museo alcanzó la mayor solidez y prestigio como institución académica. Fue el motor de una portentosa campaña de divulgación internacional para difundir una imagen de la naturaleza, los hombres, el pasado y el presente de la República Mexicana; campaña destinada a obtener el máximo reconocimiento para México y, en consecuencia, para el gobierno porfirista. A ello responde, como es bien sabido, su participación en numerosas exposiciones internacionales como la del Centenario de la Revolución Francesa (Paris 1889), la del Cuarto Centenario del Descubrimiento de América (Madrid 1892), la World's Columbian Exposition (Chicago 1893), la del 1900 (Paris 1900), la Panamericana (Buffalo 1901) y tantas otras ${ }^{10}$. Y también a ello corresponde la formidable «misión en Europa» que se encargó al propio Francisco del Paso y Troncoso ${ }^{11}$.

Sin embargo, ese período se caracteriza sobre todo por una alteración cada vez más significativa y radical de los equilibrios y de los propios contenidos del museo. No sólo hay una clara basculación hacia lo arqueológico e histórico, es

10 Véase Mauricio Tenorio Trillo, Mexico at the World's Fairs. Crafting a Modern Nation, Berkeley-Los Angeles, University of California Press, 1996; pero véase también la rica colección de materiales reunida por Daniel SchÁVELzON (comp), La polémica del arte nacional en México, 1850-1910, México, FCE, 1988 (especialmente pp. 137-197). Con respecto a la exposición madrileña de 1892 y la singular contribución mexicana, véase también Georgina RoDRíGUEZ, «Miradas sin rendición», Luna córnea 13 (sept.-dic. 1997), pp. 24-31.

11 Cf. Silvio Zavala, Francisco del Paso y Troncoso: su misión en Europa, 1892-1916, México, Publicaciones del Museo Nacional, 1938. 
que además una nueva sección llamada de Antropología y Etnografía «se fundó en octubre de 1895 por iniciativa del Sr. Lic. D. Joaquín de la Baranda, Secretario de Justicia e Instrucción Pública, con motivo de la reunión en México del undécimo Congreso de Americanistas $\rangle^{12}$. Oficialmente aparecía así, por primera vez, esta sección y este nombre en la historia de la institución y lo hizo en el contexto de una reestructuración general de notables alcances.

\section{LA ANTROPOLOGÍA ENTRA EN EL MUSEO: DOS CONGRESOS INTERNACIONALES DE AMERICANISTAS Y SUS SORPRENDENTES EFECTOS}

El XI Congreso Internacional de Americanistas, el primero que se hacía en suelo americano, fue considerado en México como un acontecimiento cultural de primer orden; como una especie de ceremonia oficial de reconocimiento internacional y «puesta de largo» de la ciencia mexicana. No es de extrañar, por tanto, que ese congreso tuviera una notable repercusión social y hasta política; ni que entre los distintos preparativos que se consideraron necesarios para su adecuada celebración, estuviera la decisión de adjudicar al museo nada menos que todo el espacio disponible en la Casa de la Moneda (edificio que hasta entonces se compartía con otras instituciones oficiales). Tal decisión permitió una notable expansión física e hizo posible una reforma en los contenidos que demostraría ser fundamental para su evolución futura. Aunque el museo siguió dividido en los tres departamentos originales de Arqueología, Historia de México e Historia Natural, el número y el carácter de las secciones concretas varió de forma muy considerable. Junto a la tradicional Galería de Monolitos, la sección de cerámica o la dedicada a la Historia Patria (de la Conquista a la República), surgió una sección nueva dedicada a la Antropología y Etnografía. Junto a las secciones tradicionales de Botánica, Zoología, Paleontología, Litología y Mineralogía, se abrieron otras nuevas de Botánica y Zoología aplicadas, Anatomía comparada y Teratología o monstruosidades ${ }^{13}$.

Sabemos que la sección de Antropología y Etnografía estaba formada por colecciones osteológicas y de cráneos, series fotográficas «de tipos del país» ${ }^{14}$, así

12 Jesús Galindo y Villa, Breve noticia histórico-descriptiva del Museo Nacional de México, México, Imprenta del Museo Nacional, 1896, p. 22 [texto clave recogido también en MoRALES MORENO [2], pp. 86].

13 Además de la descripción general del museo que aporta Galindo y VILLA [12], existen también catálogos específicos para algunas secciones; destaco especialmente el dedicado a la Galería de Monolitos, obra de Jesús Galindo y Villa, Catálogo del departamento de arqueología del Museo Nacional. Primera parte, Galería de Monolitos, México, Imprenta del Museo Nacional, 1897, y el que se elaboró para la sección antropológica, obra de Alfonso HERRERA y Ricardo CICERO, Catálogo de la colección de Antropología del Museo Nacional, México, Imprenta del Museo Nacional, 1895.

14 Estas series fotográficas, unas 600 imágenes que hoy despuertan un interés renovado, fueron realizadas por primera vez para exponerlas en Madrid en 1892 (cf. G. RoDRÍGUEZ, [10]) y se 
como cuadros estadísticos y de mediciones. Había también colecciones de «trastos, utensilios, piezas de indumentaria» y todo tipo de pertrechos utilizados por los indígenas que respondían específicamente a la parte etnográfica, pero lo cierto es que toda esta nueva sección estaba pensada como conjunto desde la Historia Natural y conceptualmente se aproximaba mucho a las otras secciones — dedicadas a la Anatomía comparada y Teratología - en la que también figuraban especímenes humanos. En realidad, todas esas secciones nuevas dedicadas al hombre compartían a grandes rasgos un programa común, y ese programa era la razón misma por la que las nuevas disciplinas antropológicas habían encontrado su lugar en el Museo Nacional.

A todas luces el objetivo era, en primer lugar, recoger la enorme variedad antropológica del país para poder racionalizarla y catalogarla en «tipos», lo que permitía fijar las distintas variedades posibles en una serie única que demostraba la existencia - al menos en teoría - de un solo «ser mexicano», así como los valores precisos atribuibles al «mexicano medio» ${ }^{15}$. Pero en segundo lugar esas secciones del museo, cada una a su manera, recogían también las aportaciones que Daniel Vergara Lope estaba haciendo a la antropología médica (especialmente sobre los problemas relacionados con la respiración en tierras altas) ${ }^{16}$ y otras como las de Francisco Martínez Baca y Manuel Vergara a la antropología criminal, muy ensalzadas estas últimas por el propio Cesare Lombroso ${ }^{17}$. Se trataba de un tipo de contribuciones con un alto nivel científico, clarísima proyección internacional ${ }^{18}$ y evidente importancia política. Su objetivo era demostrar la «norma-

recuperaron después para ser incorporadas al nuevo sistema expositivo del Museo. Según Ignacio GUTIERREZ RUVALCABA, «Antropólogos y agrónomos viajeros. Una aproximación», Alquimia, año 2, núm. 5 (1999), pp. 16-25, la nueva y muy ampliada colección fotográfica (unas 1645 imágenes) que se preparó con motivo de la celebración del XI Congreso de Americanistas tuvo una cosiderable difusión e influencia, entre otras cosas, por su impacto en la prensa nacional e internacional.

15 Sobre el origen de este concepto en México y la importancia que tuvo la estadística en su construcción y difusión, véase en el trabajo de Leticia MAYER CELIS, Entre el infierno de una realidad y el cielo de un imaginario. Estadística y comunidad científica en el México de la primera mitad del siglo XIX, México, El Colegio de México, 1999.

16 Daniel Vergara Lope, Refutación teórica y experimental de la anoxihemia del doctor Jourdanet, México, Tipografía de la Secretaría de Fomento, 1890; del mismo autor, La anoxihemia barométrica... Las tuberculosis en las altitudes... México, Oficina Tipográfica de la Secretaría de Fomento, 1893. Véase además Daniel Vergara LoPe y Alfonso L. HerRerA, La vie sur les hauts plateaux. Ouvrage couronnée par l'Institut Smithsonien de Washington (E.U.A. Concours Hodgkins - 1895), México, Imprimerie de I. Escalante, 1899.

17 Francisco Martínez BACA y Manuel Vergara, Estudios de antropología criminal. Memoria que por disposición del superior gobierno del estado de Puebla presentan para asistir a la Exposición Internacional de Chicago, Puebla, Imprenta de Benjamín Lara, 1892. Véase además la monografía de Francisco MARTínez BACA, Los tatuajes. Estudio psicológico y médico-legal en delincuentes y criminales, México, Tipografía de la Impresora del Timbre, Palacio Nacional, 1899.

18 La obra de F. MARTínez BACA y M. Vergara [17] se imprimió oficialmente con el objetivo de presentarla públicamente en la Exposición Universal de Chicago; y la de D. VERGARA LOPE y 
lidad» del tipo mexicano medio y su capacidad de adaptación compensatoria a situaciones que reconocidas autoridades internacionales definían como «anormales» porque implicaban graves «deficiencias» mentales y de carácter, como las que se atribuían a una población asentada en tierras altas con escasez de oxígeno o las que caracterizaban a un grupo humano con fuertes tendencias atávicas (inherentes a la sangre indígena) $)^{19}$.

Con esta reestructuración del museo, que se producía en el contexto singular del XI Congreso Internacional de Americanistas, México estaba respondiendo a unas necesidades científicas y políticas nuevas, que le llevaban a reconocer y dar espacio institucional privilegiado a la naciente disciplina antropológica. No se trataba de una mera concesión coyuntural sino de una tendencia profunda. La inercia perduraba todavía con claridad en 1903, cuando Nicolás León, director de la sección de Antropología del museo entre 1900 y 1907 e impulsor de numerosas exposiciones, expediciones y otras iniciativas para promover la investigación en este campo, decidió aprovechar el espacio institucional del museo — con sus ricas colecciones e instrumentos- para inciar la enseñanza formal de la Antropología en la República Mexicana. Cursos que resultaron ser verdaderamente fundacionales y que se mantendrían hasta 1916, en que fueron incorporados al currículum oficial de la Escuela Nacional de Altos Estudios ${ }^{20}$.

No obstante, el impulso final que hizo posible la transformación definitiva de la institución surgió de una coyuntura muy parecida a la que acabamos de comentar:

A. Herrera [16] es una memoria que reúne una colección de trabajos premiados en 1895 por la Smithsonian Institution e impresos en francés para darles una mayor difusión internacional.

19 Sobre estos temas véanse los trabajos de Beatriz URíAs HorCASITAS [7] y «Medir y civilizar», Ciencias 60-61 (oct. 2000- marzo 2001), pp. 28-36; así como los de Laura CHÁzARO, «La fisioantropometría de la respiración en las alturas, un debate por la patria», Ciencias 60-61 (oct. 2000- marzo 2001), pp. 37-43 y Medicina, ciencia y sociedad en México, siglo XIX, Zamora/ Morelia, El Colegio de Michoacán/ Universidad Michoacana de San Nicolás Hidalgo, 2002. Véanse además las contribuciones de Nydia CRUZ BARRERA, Las ciencias del hombre en el México decimonónico: la expansión del confinamiento, México/ Puebla, Benemérita Universidad Autónoma de Puebla, 1999 e «Indígenas y criminalidad en el porfiriato. El caso de Puebla», Ciencias 60-61 (oct. 2000- marzo 2001), pp. 50-56.

20 La historia de la antropología en México, estrechamente asociada a la arqueología científica, así como a figuras como Franz Boas o Manuel Gamio, suele estudiarse con cierto detalle sólo a partir de este punto. Véase el conjunto de trabajos reunidos por Mechtchild RUTSCH, La historia de la antropología en México. Fuentes y transmisión, México, Plaza y Valdés editores/Universidad Iberoamericana/ Instituto Nacional Indigenista, 1996 o los de Beatriz URÍAS HoRCASITAS, «Franz Boas en México, 1911-1919», Historia y grafia 16 (2001), pp. 209-248 y «Las ciencias sociales en la encrucijada del poder: Manuel Gamio (1920-1940)», Revista Mexicana de Sociología 64 (2002), pp. 93-121, aunque por supuesto existen otros muchos. Con todo, sigue mereciendo la pena ver las notas y observaciones que en fecha muy temprana hizo el propio Nicolás LEON, Notas para los alumnos de la clase de antropología física del Museo Nacional, México, Imprenta del Museo Nacional de Arqueología, Historia y Etnología, 1914 e «Historia de la antropología física en México», American Journal of Physical Anthropology II.3 (1919), pp. 229-264. 
«En 1910, el Museo se transformó para recibir en su seno al XVII Congreso Internacional de Americanistas, que celebraría en la ciudad de México su segunda sesión, de acuerdo con lo dispuesto en el Congreso celebrado en Viena en septiembre de 1908, y en homenaje a México y a la Argentina... con motivo del primer centenario de su Independencia» ${ }^{21}$.

De nuevo la celebración de un Congreso Internacional de Americanistas, que coincidía además con el Centenario de la Independencia, se consideró motivo suficiente para hacer una nueva remodelación del museo y de su sede. Y en esta ocasión, la remodelación fue verdaderamente radical. Toda la parte de Historia Natural (incluyendo las secciones de Anatomía comparada y Teratología) fue segregada para formar con ella una nueva institución: un Museo de Historia Natural propiamente dicho, cuyos fondos se completaron con colecciones procedentes de centros como el antiguo Instituto Médico Nacional o el extinguido Museo de Tacubaya (formado con los materiales recogidos por la Comisión Geográfica Exploradora). En segundo lugar, todo lo que quedó en la sede original de la Casa de la Moneda, se refundó con el nombre específico de «Museo Nacional de Arqueología, Historia y Etnología», solemnemente inaugurado el 28 de agosto de 1910, en conmemoración del Primer Centenario de la Independencia ${ }^{22}$.

El nuevo museo estaba dividido en cinco departamentos: dos correspondían a los tradicionales de Historia Patria (de la Conquista a la República) y Arqueología (con la Galería de Monolitos, la sección de cerámicas y otra más de códices). Los otros tres departamentos correspondían a Etnografía colonial y contemporánea (también conocido como de «arte industrial retrospectivo», porque su objeto de atención prioritario eran las «artes y técnicas populares»); Etnografía aborigen, a cargo de Andrés Molina Enríquez, dedicado a la etnografía propiamente dicha y que originalmente tenía también una sección de Etnografía extranjera que no cuajó; y el Departamento de Antropología física y Antropometría creado por Nicolás León a partir de la antigua sección establecida en 1895 . Hubo además un Departamento de Prehistoria general, dirigido por Jorge Engerrand, pero al igual que ocurrió con la sección «extranjera» de la Etnografía, tampoco cuajó.

De especial importancia me parece que ese mismo año de 1910 y en el contexto de la reforma impulsada por la celebración del XVII Congreso Internacional de Americanistas, el Museo — que ya albergaba las clases de antropología

21 Jesús Galindo y Villa, El Museo Nacional de Arqueología, Historia y Etnología, México, Imprenta del Museo Nacional, 1922, p. 26 [recogido parcialmente en MoRALES MoRENO [2], la referencia citada en p. 87].

22 Para conocer el museo en esta época, además de la descripción general de Jesús GALINDO Y Villa [21] y los comentarios de Luis CAstillo Ledón, El Museo Nacional de Antropología, Historia y Etnografía, 1825-1925. Reseña histórica para la celebración de su primer centenario, México, Imprenta del Museo Nacional, 1924, disponemos de toda una serie de catálogos elaborados para los distintos departamentos, como el de Nicolás LEON para el de Antropología Física: Departamento de antropología física, México, Imprenta del Museo, 1922. 
impartidas por Nicolás León — se transformara además en sede oficial de la «Escuela Internacional de Arqueología y Etnología Americanas» ${ }^{23}$. Esa Escuela Internacional, en la que desde el principio participaron figuras tan excepcionales como Eduard Seler, Franz Boas o Ales Hrdlicka, demostró ser un formidable instrumento de educación e investigación y en ella —o en su entorno- se formó toda una nueva generación de especialistas, encabezados por Manuel Gamio, cuya profesionalidad y creatividad harían posible los desarrollos nada comunes de la antropología y de la arqueología mexicanas de las siguientes décadas ${ }^{24}$. Ese orientación hacia la arqueología y antropología, cuidadosamente planificada en lo institucional, fue definitiva no tanto por la época en que se produjo o por la repercusión internacional que tuvo, sino porque se realizó a partir de una decidida voluntad política y pedagógica que la Revolución Mexicana y sus consecuencias no harían sino mantener y hasta fomentar, aunque variando matices y énfasis (se trata de uno de esos ámbitos en los que hubo más continuidad de lo que se suele supone ${ }^{25}$ ). La culminación de ese proceso - en el que los intereses políticos y científicos van de la mano - se produjo en 1940, cuando se decidió segregar del museo todas las colecciones históricas y artísticas (para formar con ellas nuevas instituciones nacionales) y dejar en la vieja sede de la Casa de la Moneda sólo las colecciones antropológicas y arqueológicas.

Nacía así definitivamente el Museo Nacional de Antropología de México, o Museo Antropológico a secas, probablemente el más representativo, el más cargado de significación y el mejor conocido del país. Ahora bien, tal como decíamos al comenzar estas líneas, el proceso institucional mexicano que acabamos de esbozar me parece todo un aldabonazo, toda una llamada de atención crítica frente a los presupuestos habitualmente sostenidos sobre el origen y conformación de la Antropología como disciplina. Un caso latinomaricano del que pueden y deben extraerse algunas conclusiones que afectan a la historia de la Antropología como disciplina en general.

23 La Escuela Internacional de Arqueología y Etnología Americanas se fundó en septiembre de 1910 bajo los auspicios de los gobiernos mexicano, alemán y francés, y con el de las universidades de Columbia, Harvard y Pennsylvania. La bibliografía sobre este tema es muy amplia, pero véase especialmente el trabajo de Guillermo de la PEÑA, «Nacionales y extranjeros en la historia de la antropología mexicana», en M. RUTSCH (comp.), La historia de la antropología en México. Fuentes y transmisión, México, Plaza y Valdés editores/Universidad Iberoamericana/ Instituto Nacional Indigenista, 1986, pp. 41-81.

24 Eduardo Matos Moctezuma, Descubridores del pasado en Mesoamérica, México, Turner, DGE Ediciones y Antiguo Colegio de San Ildefonso, 2001 ofrece un panorama general y bastante reciente sobre la historia de las investigaciones arqueológicas en México, aunque — por supuesto- la bibliografía sobre el tema es muy amplia.

25 Sobre el tema de si la Revolución Mexicana implicó la continuidad o la discontinuidad de cierto tipo de programas, me parece muy significativo el trabajo de Charles HALE, «La política científica en el Porfiriato y la Revolución Mexicana: el caso de Emilio Rabasa (1856-1930)», en Mónica QuiJada y Jesús Bustamante (eds), Élites intelectuales y modelos colectivos, mundo ibérico (siglos XVI-XIX), Madrid, CSIC, 2002, pp. 305-321. 
LAS PARADOJAS DE LA ANTROPOLOGÍA: ¿UNA CIENCIA «COLONIAL» HACIA AFUERA O UNA CIENCIA «NACIONAL» HACIA ADENTRO?

Ante todo hay que llamar la atención sobre la paradoja que representa el propio proceso institucional que acabamos de ver. Porque es bastante paradójico que la progresiva depuración de los temas y contenidos que debían caracterizar esa institución en cuanto Museo Nacional se concentre precisamente en torno a la Antropología. Recuérdese que es un tópico pocas veces cuestionado decir que la Antropología surgió como una disciplina asociada al colonialismo y que su objetivo prioritario es la definición de los «otros». Es decir que la Antropología debe entenderse como una disciplina esencialmente orientada hacia afuera, por lo que sus temas y propósitos deberían ser todo lo contrario de los adecuados para un Museo Nacional. Pues bien, el caso mexicano viene a demostrar que eso no siempre es cierto.

En realidad, la relación entre Antropología y colonialismo sólo llegó a percibirse como un problema de fondo a partir de los primeros años 70 . Y en esa percepción fueron muy importantes las denuncias lanzadas por los movimientos revolucionarios y de independencia del —entonces llamado- Tercer Mundo. Surgió así un importantísimo debate crítico —y moral — que, en su versión más extrema y reivindicativa, caricaturizó la Antropología como un mero artefacto colonial y sus aportaciones científicas como fruto exclusivo del imperialismo o del paternalismo. Debate que estuvo además en el origen de un énfasis creciente sobre los principios de «otredad» y de «enajenación» (asociados a los de «poder» $\mathrm{y}$ «discurso») que afectarían profundamente a la Antropología y a otras disciplinas relacionadas (como el llamado «orientalismo» por ejemplo) ${ }^{26}$.

Pero - a mi entender - hay una profunda contradicción entre lo que dice buena parte de esa producción crítica y la importancia que tuvo de hecho el discurso antropológico para la sociedad moderna, especialmente para los «no antropólogos». La cultura, el relativismo, el culturalismo son artefactos más o menos antropológicos que están hoy fuera del control de la disciplina, nociones que han sido generalizadas, asumiéndolas como propias los restantes miembros de nuestras sociedades. Lo mismo podría decirse de otros conceptos claves, algunos bastante antiguos, aunque no por eso menos vivos, como raza, degeneración, triunfo del más apto... o totem y tabú... Términos que acreditan, para bien o para mal, la enorme influencia que la Antropología ha tenido desde muy temprano, favore-

26 La bibliografía sobre estos temas es inmensa, un buen panorama lo ofrece George W. Stocking, Race, Culture, and Evolution: Essays in the History of Anthropology, Chicago, The University of Chicago Press, 1982, pp. xi-xxi [new preface] y «Delimiting Anthropology: historical reflexions on the bounderies of a boundless discipline», en G.W. STOcKING, Delimiting Anthropology. Occasional Essays and Reflections, Madison, The University of Wisconsin Press, 2001, pp. 303-329 (cf. especialmente pp. 320-325). No me resisto a citar los irónicos comentarios que hace Clifford GEERTZ, Reflexiones antropológicas sobre temas filosóficos, Barcelona, Paidós, 2002. 
ciendo el desarrollo de nuevas disciplinas científicas y de nuevas prácticas terapéuticas, sirviendo como referente legitimador para políticas sociales de todo signo, incorporándose al inconsciente colectivo de buena parte de la sociedad occidental desde la segunda mitad del siglo XIX en adelante.

Hay que reconocerlo, existe una profunda contradicción entre la imagen de una Antropología más bien estrecha e instrumental, asociada a la expansión colonial, y el impacto que esa misma Antropología tiene y ha tenido desde mediados del siglo XIX en la mente y el corazón de la propia sociedad occidental que la generaba. ¿Cómo explicar fenómenos como ese Museo Nacional transformado en Museo Antropológico?

Mi propuesta, y la del proyecto de investigación que estamos desarrollando actualmente en el $\mathrm{CSIC}^{27}$, es que hay que cuestionar el principio básico sobre el que se elaboró la identificación de Antropología y colonialismo. Desde luego, una disciplina que se construye esencialmente «hacia afuera» para obtener de retorno un conocimiento «útil» - es decir utilizable como instrumento de dominación- sólo puede entenderse como una variedad de industria extractiva occidental en el Tercer Mundo, o como una agencia oficial de colonización.

Pero la más mínima reflexión a partir de una experiencia empírica un poco más amplia de la que se utiliza habitualmente permite observar, de inmediato, que la relación entre Antropología y colonias es mucho menos directa, menos automática y mucho más compleja de lo que se ha venido diciendo. Para empezar, está claro que no todos los países occidentales con colonias han contribuído de la misma manera o en la misma medida a la formación, desarrollo y consolidación de la Antropología. En algunos casos, como España, Portugal y Holanda, que son los imperios coloniales más antiguos y más longevos de Europa, su contribución ha sido más bien débil y la consolidación de la disciplina sólo ha adquiriendo un cierto vigor a partir — precisamente- de la pérdida de las colonias. Así pues, si cabe sacar alguna conclusión de estas tres experiencias coloniales, las tres multiseculares, las tres de indudable complejidad e importancia, y las tres muy distintas entre sí, es que parece haber situaciones coloniales que han dificultado a sus metrópolis el desarrollo de una Antropología, aún contando con profesionales de valía e incluso habiendo intentado emular los desarrollos institucionales de otros lugares (como es sin duda el caso de Holanda).

Pero a la conclusión anterior es preciso agregar el hecho radicalmente inverso de que hubo países sin colonias que sí desarrollaron una tradición antropológica, sólo que lo que les interesaba o «extrañaba» a estos antropólogos eran sus propios conciudadanos o, al menos, algunos de ellos. El caso más simple y conocido de estas tradiciones antropológicas claramente orientadas «hacia adentro» es probablemente el italiano, el de Cesare Lombroso y su influyente escuela de antro-

27 El proyecto se titula «Ingenieros sociales. La construcción del método y el pensamiento antropológicos en Europa e Iberoamérica, siglo XIX». Véase nota 1. 
pología criminal. Es bien sabido que, antes de la formación de su imperio colonial pero coincidiendo con el momento en que se constituía como estado nacional, Italia articuló una propuesta antropológica completa cuyo objetivo prioritario era la población europea. Mejor dicho, el objetivo era la población italiana propiamente dicha, a la que había que singularizar a partir de su comparación con la de otros lugares $^{28}$. Es cierto que en la actualidad Lombroso y su escuela - que es más que criminalista - suelen ser tildados de poco antropológicos y de demasiado juristas o forenses, quizá porque es una herencia que pocos quieren asumir; por eso conviene recordar que se trata de una teoría antropológica completa, maravillosamente sencilla en su articulación y convincentemente construída desde un punto de vista científico, tanto por su lenguaje como por sus tablas y cuadros estadísticos. Cosa distinta es que no nos guste. Pero lo cierto es que esta aportación italiana representa una tendencia de pensamiento y de actuación antropológicos de enorme influencia en Europa y América. Su propia existencia y la manera en que se difundió demuestran por sí mismas que en el proceso de construcción e institucionalización de la Antropología existió al menos un segundo motor social, muy diferente al que nos era conocido a partir de la teoría colonialista. Y la importancia que realmente tuvo ese segundo motor queda al descubierto de una forma meridiana en el caso verdaderamente ejemplar de la Antropología alemana.

Porque la Antropología alemana es incuestionablemente una de las grandes tradiciones, junto a la inglesa o la francesa, que conforman la disciplina actual en todos sus campos. Suele decirse que su contribución más importante es la noción de cultura, tanto en su sentido material exponible en las vitrinas de un museo y clasificable por áreas y rasgos; como en su sentido más espiritual y psicológico que remite a ese contexto de hábitos, prácticas y creencias en el que se crían y conforman los individuos, contexto a partir del cual debe explicarse su comportamiento, sus reacciones, sus creaciones... Pero lo cierto es que a la tradición alemana se deben otras muchas contribuciones, tanto en lo teórico, como en el nivel pragmático o institucional. Y la gran mayoría de esas aportaciones se produjeron antes, incluso mucho antes, de que Alemania se planteara la posibilidad misma de tener un imperio colonial, imperio que por otra parte resultó bastante efímero. Más aún, todas esas aportaciones a la Antropología se produjeron a partir de problemas y debates «internos», que afectaban a una Alemania en pleno proceso de construcción nacional ${ }^{29}$.

28 Una visión general sobre la antropología italiana del período, con rica bibliografía, puede encontrarse en Sandra PUCCINI, «Institutionnalisation de l'anthropologie italienne au XIXe siècle», Gradhiva 9 (1991), pp. 63-76; en cuanto a Lombroso y su escuela, la bibliografía es muy abundante y desigual; un panorama general, con rica selección de textos, puede encontrarse en José Luis PESET y Mariano PeSET(eds), Lombroso y la escuela positivista italiana, (col. Clásicos de la Medicina), Madrid, CSIC, 1975.

29 Sobre la antropología alemana véanse especialmente los trabajos de Matti BuNZL, «Franz Boas and the Humboldtian Tradition: From Volksgeist and Nationalcharakter to an Anthropologi- 
Por ejemplo, la noción de Kultur es el fruto complejo y fascinante del agrio conflicto que enfrentó la poderosa escuela humanística alemana, regida por historiadores y filólogos, con la nueva y no menos poderosa escuela cuyo centro era la Historia Natural y la Medicina. No se trataba de un debate erudito, sino del enfrentamiento entre dos modos de entender las ciencias y la educación, lo que en la Alemania de la época equivalía a dos maneras de entender la política y la propia sociedad.

La gran Antropología alemana, la que impulsaron e institucionalizaron dos médicos como A. Bastian y R. Virchow, desde el principio fue una propuesta que - tanto en lo intelecutal como en lo pragmático - formaba parte del proyecto renovador y crítico del partido liberal progresista para la Alemania unificada. Y no me refiero a una vinculación meramente simbólica o indirecta. Rudolf Virchow, figura todopoderosa, fundador y presidente por largos años de la Sociedad Antropológica Alemana (1869 Deutsche Gesellschaft für Anthropologie, Ethnologie und Urgeschichte), fue antes que nada un político fundador del Partido Alemán Progresista (1861 Deutsche Fortschrittspartei) y diputado en el Parlamento Nacional Alemán (el Reichstag) entre 1880 y 1893, y en el prusiano desde la década de 1860 hasta su muerte en $1902^{30}$.

Virchow organizó explícitamente la Sociedad Antropológica Alemana en 1869 como una «república científica», cuidadosamente federada y articulada con la finalidad de liderar la llamada Kulturkampf — la guerra cultural — de la década de 1870 . Su primer proyecto de envergadura, realizado entre 1873 y 1875 , fue el relevamiento estadístico de la propia población alemana, de sus tipos, formas, colores y confesiones.... Proyecto ambiciosísimo asumido por el Estado, que no sólo hizo que colaboraran los cuarteles y sobre todo los maestros de escuela repartidos por todo el territorio nacional (por eso este proyecto suele ser conocido

cal Concept of Culture», en G. STOCKING (ed), «Volkgeist» as Method and Ethic. Essays on Boasian Ethnography and the German Anthropological Tradition (col. History of Anthropology, 8), Madison, University of Wisconsin Press, 1996, pp. 17-78; Andrew ZimMERMAN, Anthropology and Antihumanism in Imperial Germany, Chicago, The University of Chicago Press, 2001; y el conjunto de estudios reunidos por H. Glenn PENNY y Matti BunzL, Worldly Provincialism. German Anthropology in the Age of Empire, Ann Arbor, The University of Michigan Press, 2003.

30 Sobre Rudolf Virchow, figura verdaderamente compleja, además de las referencias generales que pueden encontrarse en la bibliografía mencionada sobre la tradición antropológica alemana, existen varias monografías específicas: la clásica de Erwin H. ACKERKNECHT, Rudolf Virchow: Doctor, Statesman, Anthropologist, Madison, University of Wisconsin Press, 1953; y las más recientes de Christian ANDREe, Rudolf Virchow als Prähistoriker, Köln, Böhlau, 1976 y Rudolf Virchow: Leben und Ethos eines grossen Arztes, München, Langen Müller, 2002; así como la de Constantin Goschler, Rudolf Virchow: Mediziner, Anthropologe, Politiker, Köln, Böhlau, 2002. Existen además otras obras menores, pero no menos útiles, como por ejemplo Marion BERTRAM, Rudolf Virchow als Prähistoriker. Sein Wirken in Berlin, Berlin, Museum für Ur- und Frühgeschichte, 1987, o Geraldine Saherwala, Thomas Schmalke, Konrad Vanja und Han-Joachim VeIge (eds), Zwischen Charité und Reichstag. Rudolf Virchow Medizines, Sammler, Politiker, Berlin, Berliner Medizinhistorisches Museum der Charité, 2002. 
como la Schulstatistik), sino que además prestó los servicios de la Real Oficina Prusiana de Estadística para el manejo de datos tan complejos y numerosos. Un proyecto verdaderamente movilizador de recursos y personas y un proyecto antropológico declarademente dirigido «hacia adentro», tanto que a él se debe la definición del «tipo alemán» y sus variantes, así como la del «tipo judío», por ejemplo. Así pues, el primer objeto privilegiado de estudio para la Sociedad Antropológica Alemana fue la propia población alemana, y su primer objetivo expreso fue la definición étnica y racial de los pobladores de esa nueva nación unificada.

Estamos hablando del proyecto antropológico más complejo de la época, admirado y reconocido por todas las sociedades científicas de entonces. De hecho llegó a ser emulado y hubo otros proyectos similares entre los que debe destacarse, claro está, el emprendido por Inglaterra entre 1875 y 1883 para el estudio de la población británica, sus características y tipos raciales. Complejo proyecto que culminaría con los trabajos de J. Beddoe y F. Galton. El primero introdujo las definiciones canónicas del judio, irlandés, galés o anglosajón como tipos raciales del Reino Unido; el otro sentó las bases de la eugenesia; en ambos casos se trata de aportaciones antropológicas de un gran impacto social que demuestran cómo en Inglaterra también hubo desde el principio una Antropología orientada «hacia adentro» que era además la que proporcionaba a la disciplina mayor legitimación y mayores recursos.

Es decir, tanto en Inglaterra, como en Alemania e Italia, y seguramente también en otros lugares, como demuestra el caso mexicano que ha sido nuestro punto de partida, encontramos una Antropología estrechamente asociada a la propia población nacional y sus problemas específicos. Una Antropología que surge en el momento de formación de los estados-nacionales y que debe a esa dimensión «nacional» propia - y no a la «colonial»- buena parte de su capacidad de financiación, institucionalización e incidencia social.

La obsesión por identificar la Antropología con pueblos colonizados y cuanto más primitivos mejor, ha oscurecido e incluso borrado cuáles fueron las actividades que muchos de los antropólogos desempeñaron en los años de formación de la disciplina, aquéllos en los que no casualmente tuvo una mayor influencia sobre la mentalidad colectiva occidental. Por ejemplo, el ya varias veces citado Rudolf Virchow estuvo detrás de los proyectos que intentaban hacer de Berlín una ciudad más saludable y fue él quien avaló las reformas del sistema sanitario y de alcantarillado. Sin duda una tarea singular para un antropólogo, pero es que la Antropología, en manos de figuras como Virchow y tantos otros de sus contemporáneos, era esencialmente un instrumento educativo, un arma para la reforma de las costumbres, un medio para la mejora de la sanidad, la higiene, las prácticas terapéuticas.... $\mathrm{y}$, por supuesto, un referente valiosísimo para definir la propia nacionalidad $\mathrm{o}$, mejor todavía, para definir el ideal al que era deseable que se aproximaran nuestros conciudadanos. 
La Antropología, vista desde esta óptica y desde estos ejemplos que me parecen paradigmáticos, habría surgido disciplinarmente y se habría consolidado institucionalmente en el contexto de una acción social y política comprometida con los propios ciudadanos, y no tanto con los problemas derivados de la administración de los pueblos primitivos o colonizados.

La Antropología se nos presenta así como una disciplina que mira «hacia dentro» y cuyos objetivos prioritarios estarían en el « interior» de la propia sociedad. Una disciplina, eso sí, que que para realizar su tarea, para afilar sus instrumentos conceptuales - y hasta morales o políticos - necesita «mirar hacia afuera» y comparar, mostrando la diversidad, relativizando las tradiciones y las herencias ... Y esa mirada «a lo lejos», entendida como una hermenéutica, ha sido uno de sus rasgos más distintivos hasta el día de hoy. Sin duda, la expansión colonial ofreció un campo abonado para su desarrollo profesional y para su aplicabilidad en espacios ultramarinos. Pero tal especialización — característica de las tradiciones inglesa y francesa - no debe hacernos olvidar que también existieron otros desarrollos no menos importantes y otras aplicaciones que se hicieron en espacios «dentro del territorio nacional» y sobre poblaciones a las que no les quedaba otra elección que extinguirse, marcharse a otro sitio o volverse «conciudadanos». Precisamente eso, y no una expansión colonial, es lo que ocurre en Estados Unidos, creador de una tradición antropológica cuya importancia nadie puede negar. Y algo muy parecido ocurre también en los distintos países de Latinoamérica, cada uno a su manera y con niveles de institucionalización o reconocimiento muy distintos, pero que hasta ahora hemos estudiado poco o conocemos mal.

$\mathrm{Y}$ de todo esto es de lo que nos habla, lo que nos pone delante de los ojos, esa sorprendente andadura - de lo «nacional» a lo «antropológico»— emprendida por el Museo de México y llevada a cabo por unos hombres que no sólo fueron científicos responsables, sino además patriotas comprometidos en un proyecto colectivo, que no era otro que el de la construcción nacional. Sólo el prejuicio de lo que se supone que debe ser la Antropología, unido al prejuicio del escaso valor paradigmático que se otorga a las experiencias latinoamericanas, puede explicar que no se haya visto antes la riqueza y el interés de un caso como éste.

This work analyses the process through which the Mexican National Museum - originally embracing all branches of knowledge - reached both institutional maturity and highest social significance in the form of an Anthropological Museum. This case study shows how necessary it is to critically reformulate the current presuppositions and theories dealing with the origin and institutionalization of Anthropology as a discipline. nialism.

Key words: National Museum, Anthropology, historical memories, national population, Colo- 